\title{
Measurement of Ascorbic Acid and Glutathione Content in Cyanobacterium Synechocystis sp. PCC 6803 \\ Anabella Aguilera ${ }^{1, ~}$, Charlotte Steelheart ${ }^{2, \#}$, Matías Alegre", \#, Federico Berdun ${ }^{1}$, Graciela Salerno, Carlos Bartoli ${ }^{2}$, Gabriela Pagnussat ${ }^{3, *}$ and María Victoria Martin ${ }^{1, *}$
}

${ }^{1}$ Instituto de Investigaciones en Biodiversidad y Biotecnología (INBIOTEC-CONICET), Fundación para Investigaciones Biológicas Aplicadas (CIB-FIBA), Vieytes 3103, Mar del Plata, Argentina; '2Instituto de Fisiología Vegetal (INFIVE), Facultades de Ciencias Agrarias y Forestales y de Ciencias Naturales y Museo, Universidad Nacional de La Plata, CCT-CONICET La Plata, cc 327, 1900, La Plata, Argentina; ${ }^{3}$ Instituto de Investigaciones Biológicas IIB-CONICET- Universidad Nacional de Mar del Plata, Funes

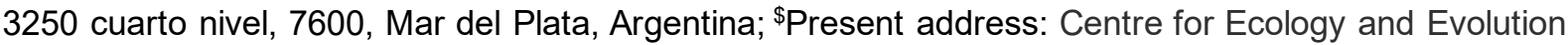
in Microbial Model Systems, Linnaeus University, Kalmar, Sweden

\#Contributed equally to this work

*For correspondence: gpagnussat@mdp.edu.ar; victoriamartin78@gmail.com

[Abstract] Ascorbic acid (AsA) and gluthathione (GSH) are two key components of the antioxidant machinery of eukaryotic and prokaryotic cells. The cyanobacterium Synechocystis sp. PCC 6803 presents both compounds in different concentrations (AsA, 20-100 $\mu \mathrm{M}$ and GSH, 2-5 mM). Therefore, it is important to have precise and sensitive methods to determine the redox status in the cell and to detect variations in this antioxidants. In this protocol, we describe an improved method to estimate the content of both antioxidants (in their reduced and oxidized forms) from the same sample obtained from liquid cultures of Synechocystis sp. PCC 6803.

Keywords: Cyanobacteria, Antioxidants, Glutathione, Ascorbic acid, Oxidative stress

[Background] The redox status in the cell can be altered by multiple factors generating oxidative stress. We used this protocol to quantify GSH and AsA contents in Synechocystis sp. PCC 6803 exposed to heat $\left(50^{\circ} \mathrm{C}\right)$. As described for Arabidopsis thaliana, heat stress resulted in a decline in the content of both antioxidants and triggered cell death by ferroptosis (Distéfano et al., 2017; Aguilera et al., 2019 preprint). Although this protocol was set for Synechocystis sp. PCC 6803, it can be applied to determine GSH and AsA contents in other cyanobacteria. In cyanobacteria AsA contents are very low, uM range in normal conditions and pM under some treatments. For that reason we propose this senstitive method with an improved cell lysate procedure. 


\section{Materials and Reagents}

1. Pipette tips: $0.1-10 \mu \mathrm{l}, 1-200 \mu \mathrm{l}$ and $100-1,000 \mu \mathrm{l}$

2. $1.5 \mathrm{ml}$ microcentrifuge tubes

3. $50 \mathrm{ml}$ conical centrifuge tubes

4. Sterile syringes: $1 \mathrm{ml}$ and $10 \mathrm{ml}$

5. Sterile acid-washed glass beads (150-212 $\mu \mathrm{m})$ (Sigma-Aldrich, catalog number: G1145)

6. $0.22 \mu \mathrm{m}$ nylon menbrane filters (e.g., GVS, catalog number: FJ13BNPNY002AD01)

7. Synechocystis PCC 6803 liquid cultures

8. Ice

9. Liquid nitrogen

10. Sterile Mili-Q water

11. Water for HPLC (Sigma-Aldrich, catalog number 900682)

12. Bond Elut $C 18$ cartridges (Agilent Technologies, catalog number: 12102028)

13. TFA (Trifluoroacetic acid) (Carlo Erba, catalog number: 411564)

14. DTT (Dithiothreitol) (Sigma-Aldrich, catalog number: D0632)

15. Methanol HPLC-grade (Sigma-Adrich, catalog number: 34860)

16. Phosphoric acid for HPLC (85\%) (Sigma-Adrich, catalog number: 49685)

17. Potassium phosphate dibasic (Sigma-Aldrich, catalog number: P8281)

18. Potassium dihydrogen phosphate anhydrous (Sigma-Aldrich, catalog number: 543841)

19. Ethylenediaminetetraacetic acid (EDTA) (Sigma-Aldrich, catalog number: 431788)

20. NADPH ( $\beta$-Nicotinamide adenine dinucleotide 2'-phosphate reduced tetrasodium salt hydrate $\geq 93 \%$ (HPLC) (Sigma-Aldrich, catalog number: N1630)

21. DTNB (5,5'-Dithiobis(2-nitrobenzoic acid)) (Sigma-Aldrich, catalog number: D8130)

22. GSSG (L-Glutathione oxidized) (Sigma-Aldrich, catalog number: G4376)

23. Glutathione Reductase from bakers yeast ( $S$. cerevisiae) (Sigma-Aldrich, catalog number: G3664)

24. 4-Vinylpyridine (Sigma-Aldrich, catalog number: V3204)

25. L-Glutathione reduced (Sigma-Aldrich, catalog number: G4251)

26. L-Ascorbic acid (Sigma-Aldrich, catalog number: A5960)

27. Neubauer counting chamber (Brand ${ }^{\mathrm{TM}}$ Blaubrand $^{\mathrm{TM}}$, catalog number: 10350141)

28. Phosphate buffer $100 \mathrm{mM} \mathrm{pH7}$ (see Recipies)

29. Phosphate buffer 100 mM pH 7.5 + EDTA 5 mM (see Recipies)

\section{Equipment}

1. Pipettes

2. Neubauer counting chamber 
3. Refrigerated centrifuge $\left(50 \mathrm{ml}\right.$ conical tubes: Thermo Scientific ${ }^{\mathrm{TM}}$, model: IEC ${ }^{\mathrm{TM}} \mathrm{CL} 31 ; 1.5 \mathrm{ml}$ tubes: Thermo Scientific ${ }^{\mathrm{TM}}$, model: Sorvall ${ }^{\mathrm{TM}}$ Legend $^{\mathrm{TM}}$ Micro 17R)

4. Vortex mixer (Scientific Industries, model: VORTEX-GENIE 2)

5. Spectrophotometer (Shimadzu, model: UV-160A-Vis)

6. pH-meter (Milwaukee, model: MI-150, catalogue number: 11861)

7. HPLC system (Shimadzu Scientific Instruments) equipped with:

a. LC pump (Shimadzu Scientific Instruments, model: LC-10 AT)

b. UV-VIS detector (Shimadzu Scientific Instruments, model: SPD-10AV)

c. Microsphere C-18 column (Agilent technologies, SS $100 \times 4.6 \mathrm{~mm}, 3 \mu \mathrm{m}$; catalog number: CP28076)

\section{Software}

1. Microsoft Excel (Microsoft Corporation, Available from: https://office.microsoft.com/excel)

\section{Procedure}

A. Cell harvest and antioxidants extraction

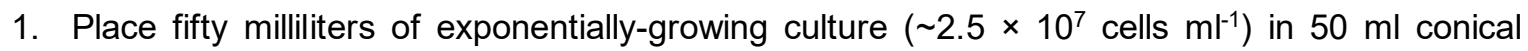
centrifuge tubes.

2. Harvest cells by centrifugation $\left(9,300 \times g\right.$ for $\left.10 \mathrm{~min}, 4^{\circ} \mathrm{C}\right)$.

3. Discard the supernatant and place the pellet with a sterile spatula in a new and sterile $1.5 \mathrm{ml}$ microcentrifuge tube.

4. Place the tube on ice. Resuspend cells in $1 \mathrm{ml} \mathrm{3 \%}$ TFA and add approximately $100 \mu \mathrm{l}$ of sterile acid-washed glass beads $(150-212 \mu \mathrm{m})$.

5. Lyse the cells by mixing vigorously (vortex, $1 \mathrm{~min}$ ), freeze with liquid nitrogen and thaw in ice. Note: Broken cells can be observed under an optical microscope, in order to ensure a correct rupture of the cells.

6. Repeat Step A5 at least 3 times.

7. Centrifuge the homogenate $\left(16,000 \times g 15 \mathrm{~min}, 4^{\circ} \mathrm{C}\right)$.

8. Collect the supernatant in a new $1.5 \mathrm{ml}$ microcentrifuge tube and keep it on ice before use.

9. Activate Bond Elut $\mathrm{C} 18$ columns by applying in the following order:

a. $1.5 \mathrm{ml}$ methanol.

b. $1.0 \mathrm{ml}$ water for HPLC.

c. $1.0 \mathrm{ml}$ phosphate buffer $100 \mathrm{mM} \mathrm{pH} 7.00$.

Discard the solution from the washing steps.

10. Pass $500 \mu \mathrm{l}$ of the supernantant (Step A8) through a previously activated Bond Elut C18 cartridge using a siringe.

11. Discard flow-through $(500 \mu \mathrm{l})$ and pass $1.5 \mathrm{ml}$ phosphate buffer $100 \mathrm{mM} \mathrm{pH} 7.00$ to elute $(\mathrm{pH}$ 
of the elution around 2). Collect the filtrate in a new $1.5 \mathrm{ml}$ microcentrifuge tube and mix thoroughly by vortexing for $10-20 \mathrm{~s}$.

This filtrate is used for ascorbic acid and glutation determination.

Note: It is highly recommended to perform the measurements inmediately after obtaining the filtrate. In particular, ascorbic acid determination needs to be done after the preparation. Freezing the samples is not recommended because after thawing a drastic reduction in the antioxidant content is observed. For glutathione measurements, the supernatant can be stored at $-80^{\circ} \mathrm{C}$.

B. Reduced ascorbic acid and total ascorbate measurements

1. To determine reduced ascorbic acid mix in a new $1.5 \mathrm{ml}$ microcentrifuge tube:

$240 \mu \mathrm{l}$ of the filtrate obtained in Step A10

$240 \mu \mathrm{l}$ of $\mathrm{K}_{2} \mathrm{HPO}_{4} 100 \mathrm{mM} \mathrm{pH} 8.5$

$50 \mu \mathrm{l}$ of TFA $10 \%$

$15 \mu$ l of water for HPLC

2. To determine total ascorbate mix in a new $1.5 \mathrm{ml}$ microcentrifuge tube:

$240 \mu \mathrm{l}$ of the filtrate obtained in Step A10

$240 \mu \mathrm{l}$ of $\mathrm{K}_{2} \mathrm{HPO}_{4} 100 \mathrm{mM} \mathrm{pH} 8.5$

$15 \mu$ of DTT $100 \mathrm{mM}$ (final concentration: $3 \mathrm{mM}$ )

Incubate for $5 \mathrm{~min}$ at at room temperatur and stop the reaction by adding $50 \mu$ of TFA $10 \%$.

C. Reduced ascorbic acid and total ascorbate quantification

1. To quantify the reduced ascorbic acid concentration, filter the solution obtained in Step B1 through a $0.22 \mu \mathrm{m}$ nylon menbrane filter and inject $10 \mu \mathrm{l}$ in a HPLC equipped with and a C-18 column $(100 \times 4.6 \mathrm{~mm}, 3 \mu \mathrm{M})$. As mobile phase use a solution of $\mathrm{KH}_{2} \mathrm{PO}_{4} 100 \mathrm{mM}(\mathrm{pH} 3.00)$ in water for HPLC (adjust pH with phosphoric acid $85 \%$ ) at 0.35 and $0.5 \mathrm{ml} \mathrm{min}^{-1}$ flow.

2. Quantify the area under the peak that displays a maximum at $265 \mathrm{~nm}$ (Figure 1).

3. To quantify total ascorbate concentration filter and inject $10 \mu \mathrm{l}$ of the second solution obtained in step B2 using the same equipment and conditions described in Steps C1 and C2.

4. Prepare a calibration curve using a series of standard L-ascorbic acid dilutions (e.g., final concentrations of $0.1,0.5$ and $1 \mu \mathrm{M}$ ) and measure the peak area following the same procedure as described in Step C2 (Figure 1).

5. Adjust the linear function of ascorbic acid concentration vs. peak area and use the slope to calculate the concentration of the unknown samples as described in the formula:

Total ascorbate or reduced ascorbic acid ( $\mu \mathrm{mol} / \mathrm{mg}$ fresh weigh)

$=\frac{\text { curve slope } x \text { peak area }\left(\frac{\text { picomol }}{m l}\right) \times 1000000 \times \text { final volume of the eluate }(\mathrm{ml})}{\text { sample weight }(\mathrm{mg})} \times 2 \times 3$ 
The $x 2$ is included in the formula because cells are resuspended in 1 mI TFA (Step A4) but only half of the supernatant is passed trought the column (Step A9). The $x 3$ is included because in Step A10 one volume of sample is passed through the column $(500 \mu \mathrm{l})$ and three volumes are collected $(1.5 \mathrm{ml})$.

\begin{tabular}{|c|c|}
\hline $\begin{array}{c}\text { A } \\
\text { Area under } \\
\text { the peak }\end{array}$ & $\begin{array}{c}\text { B } \\
\text { Ascorbic acid } \\
\text { (picomols) }\end{array}$ \\
\hline 932838 & 1000000 \\
\hline 988386 & 1000000 \\
\hline 1038861 & 1000000 \\
\hline 462142 & 500000 \\
\hline 503082 & 500000 \\
\hline 464245 & 500000 \\
\hline 108186 & 100000 \\
\hline 95356 & 100000 \\
\hline 97380 & 100000 \\
\hline
\end{tabular}

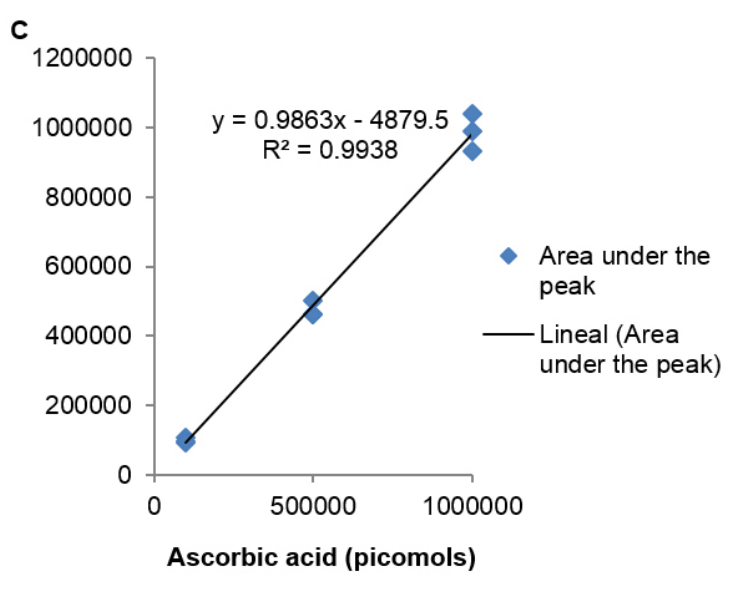

Figure 1. Area under the peak and standard curve to Asa quantification

D. Measurement of glutathione content

The quantitative determination of the total amount of glutathione (GSH + GSSG) employs an enzymatic method. In this, the reduction of DTNB to 5-thio-2-Nitrobenzoato (TNB) by NADPH is quantified spectrophotometrically. This reaction is used to measure the reduction of GSSG to GSH. The rate of the reaction is proportional to the GSH and GSSG concentration.

1. To determine the total glutathione, in a new $1.5 \mathrm{ml}$ microcentrifuge tube add:

$650 \mu \mathrm{l}$ phosphate buffer $100 \mathrm{mM} \mathrm{pH} 7.5+$ EDTA $5 \mathrm{mM}$

$25 \mu \mathrm{INNB}(5 \mathrm{mg} / \mathrm{ml}$ ) (final concentration $0.2 \mathrm{mM}$ )

$5 \mu \mathrm{IADPH}(1 \mathrm{mg} / 100 \mu \mathrm{l})$

$5 \mu \mathrm{l} \mathrm{I} \mathrm{glutathione} \mathrm{reductase} \mathrm{1:30} \mathrm{(0.5} \mathrm{U)}$

$300 \mu \mathrm{l}$ of filtrate obtained in Step A10

Note: The blank solution contained all reagents except the filtrate obtained in Step A10.

2. Mix gently and read the absorbance at $412 \mathrm{~nm}$ using a spectrophotometer.

3. To extract the oxidized gluthathion (GSSG), add $3 \mu \mathrm{l}$ of Vinylpyridine (95\%) to $300 \mu \mathrm{l}$ of the filtrate obtained in Step A10, gently mix by vortexing and incubate at room temperature for 25 $\min$.

4. Centrifuge $\left(16,000 \times g 10 \mathrm{~min}, 4^{\circ} \mathrm{C}\right)$ and place the tube on ice

5. In a new $1.5 \mathrm{ml}$ microcentrifuge tube add $365 \mu \mathrm{l}$ phosphate buffer $100 \mathrm{mM}$ pH $7.5+$ EDTA $5 \mathrm{mM}$. 
$25 \mu \mathrm{D}$ DNTB $(5 \mathrm{mg} / \mathrm{ml})$.

$5 \mu \mathrm{I}$ NADPH $(1 \mathrm{mg} / 100 \mu \mathrm{l})$

$5 \mu \mathrm{l} \mathrm{I} \mathrm{glutathione} \mathrm{reductase} \mathrm{1:30} \mathrm{(0.5} \mathrm{U)}$

$100 \mu \mathrm{l}$ of the supernatant obtained in Step D4

6. Mix gently and read the absorbance at $412 \mathrm{~nm}$.

7. Quantification of glutathione levels is based on the oxidized form of glutathione (GSSG). To quantify the glutathione levels, prepare a calibration curve with 0-100 $\mu \mathrm{M}$ standard L-Glutathione oxidized solution.

Note: The content of the antioxidant can be expressed either as per mg of fresh or dry weight or as pmol per cell (in the case of of ascorbic acid) and nmol per cell (in the case of glutathione). The content of antioxidants can be correlated with cell number determined with a Neubauer counting chamber.

\section{Recipes}

1. Phosphate buffer $100 \mathrm{mM} \mathrm{pH} 7$

Add $1.071 \mathrm{~g} \mathrm{~K}_{2} \mathrm{HPO}_{4}$ and $0.524 \mathrm{~g} \mathrm{KH}_{2} \mathrm{PO}_{4}$ in $100 \mathrm{ml}$ Sterile Mili-Q water

2. Phosphate buffer $100 \mathrm{mM} \mathrm{pH} 7.5+$ EDTA $5 \mathrm{mM}$

Solution 1: mix $0.681 \mathrm{~g}$ of $\mathrm{KH}_{2} \mathrm{PO}_{4}$ and $0.093 \mathrm{~g}$ of EDTA in $50 \mathrm{ml}$ sterile Mili-Q water Solution 2: mix $0.871 \mathrm{~g}$ of $\mathrm{K}_{2} \mathrm{HPO}_{4}$ and $0.093 \mathrm{~g}$ of EDTA in $50 \mathrm{ml}$ sterile Mili-Q water Adjuts the $\mathrm{pH}$ of solution 2 by adding solution 1 till reach $\mathrm{pH} 7.5$

\section{Acknowledgments}

This research was funded by grants to M.V. Martin from Agencia Nacional de Promoción Científica y Técnica Argentina (PICT 1956 and PICT 0173) and to G.C. Pagnussat from Agencia Nacional de Promoción Científica y Técnica Argentina (PICT-2017-0201).

This protocol was adapted from previously published studies (Griffith, 1980; Bartoli et al., 2006; Narainsamy et al., 2016).

\section{Competing interests}

The authors declare no competing financial interests.

\section{References}

1. Aguilera, A., Berdun, F., Bartoli, C., Steelheart, C., Alegre, M., Salerno, G., Pagnussat, G. and Martin, M. V. (2019). Heat stress induces ferroptosis in a photosynthetic prokaryote. bioRxiv: 
828293.

2. Bartoli, C. G., Yu, J., Gómez, F., Fernández, L., McIntosh, L. and Foyer, C. H. (2006). Interrelationships between light and respiration in the control of ascorbic acid synthesis and accumulation in Arabidopsis thaliana leaves. $J$ Exp Bot 57(8): 1621-1631.

3. Distéfano, A. M., Martin, M. V., Córdoba, J. P., Bellido, A. M., D'Ippólito, S., Colman, S. L., Soto, D., Roldán, J. A., Bartoli, C. G., Zabaleta, E. J., Fiol, D. F., Stockwell, B. R., Dixon, S. J. and Pagnussat, G. C. (2017). Heat stress induces ferroptosis-like cell death in plants. J Cell Biol 216(2): 463-476.

4. Griffith, O. W. (1980). Determination of glutathione and glutathione disulfide using glutathione reductase and 2-vinylpyridine. Anal Biochem 106(1): 207-212.

5. Narainsamy, K., Farci, S., Braun, E., Junot, C., Cassier-Chauvat, C. and Chauvat, F. (2016). Oxidative-stress detoxification and signalling in cyanobacteria: the crucial glutathione synthesis pathway supports the production of ergothioneine and ophthalmate. Mol Microbiol 100(1): 1524. 